\title{
Hemophagocytic syndrome secondary to SARS-Cov-2 infection: a case report
}

\author{
Marco Meazza Prina, Francesca Martini*, Federico Bracchi, Daniela Di Mauro, Anna Fargnoli, Marco Motta, \\ Cristina Giussani, Giovanni Gobbin, Monica Taverna and Andrea D’Alessio
}

\begin{abstract}
Background: Hemophagocytic syndrome (HPS) is a severe hyperinflammatory disease, whose diagnosis is based on the HLH-2004 criteria. In secondary forms of HLH (sHLH), the primary goal is treating the triggering factors such as COVID-19 (Coronavirus disease 2019). The link between the cytokine storm related to COVID-19 and development of sHLH has already been reported since the onset of pandemic, but little is known about clinical manifestations of HLH which develop after the patient's recovery from mild symptomatic or asymptomatic Sars-CoV-2 infection.
\end{abstract}

Case presentation: We describe the case of a woman diagnosed with sHLH related to previous Sars-CoV-2 infection and successfully treated with steroids, colchicine, etoposide and ruxolitinib.

Conclusions: Our report suggests that HLH-like syndrome might be secondary to Sars-CoV-2 infection, even if the patient utterly recovered from the mildly symptomatic viral infection. In addition, we underline the treatment with low dose ruxolitinib plus etoposide as a potential choice for Sars-CoV-2 infection related HLH.

Keywords: Hemophagocytic syndrome, COVID-19, Polyserositis, Case report

\section{Background}

Hemophagocytic syndrome (HPS) or hemophagocytic lymphohistiocytosis (HLH) is a severe hyperinflammatory disease, determined by a dysregulated activation of macrophages and cytotoxic T cells. Two kinds of HPS have been described: the primary form, caused by mutations affecting immune system and mainly common among paediatric patients and the secondary (or acquired) form, potentially triggered by several different diseases such as infections (mostly viral infections), malignancies (in particular malignant lymphomas), macrophage activation syndrome (MAS) in autoimmune/ autoinflammatory disorders and novel immunotherapies (CART cells and blinatumumab) [1-6].

*Correspondence: m_88_f@libero.it

Department of Internal Medicine and Onco-Haematology Policlinico

S.Marco, GSD University and Research Hospital, Corso Europa 7,

24040 Zingonia, BG, Italy
The diagnosis is based on the HLH-2004 criteria [7]. The most recent HLH probability score (Hscore) may be a helpful diagnostic tool at the patient's initial presentation [8]. Moreover, hyperbilirubinemia, hepatomegaly, elevated LDH and D-dimer levels are common features of $\mathrm{HLH}$, even if not included in HLH-2004 criteria. Mortality of HLH remains high in adults, around $70 \%$, despite therapy [9]. In secondary forms of HLH (sHLH), the primary goal is treating the triggering factors such as Sars-CoV-2 infection. The link between the cytokine storm related to COVID-19 and development of sHLH has already been reported since the onset of pandemic [9], but little is known about clinical manifestations of HLH which develop after patient's recovery from SarsCoV-2 infection. Of note, in COVID-19 related sHLH, hemophagocytosis on bone marrow biopsy has not been reported so far [10]. Early high dose steroids and IVIG $(1 \mathrm{~g} / \mathrm{kg})$ for 2 days are considered the first line treatment of sHLH. The first cases of macrophage-activation syndrome (MAS) in association with COVID-19 were 
Table. 1 HScore for reactive hemophagocytic syndrome

\begin{tabular}{|c|c|c|c|}
\hline Variable & Points & & Patient's score \\
\hline \multirow{2}{*}{$\begin{array}{l}\text { Known underlying immunosuppression } \\
\text { HIV positive or receiving long-term immunosuppressive therapy } \\
\text { (i.e., glucocorticoids, cyclosporine, azathioprine) }\end{array}$} & No & 0 & No \\
\hline & Yes & +18 & \\
\hline \multirow[t]{3}{*}{ Temperature, ${ }^{\circ} \mathrm{F}\left({ }^{\circ} \mathrm{C}\right)$} & $<101.1(<38.4)$ & 0 & \\
\hline & $101.1-102.9(38.4-39.4)$ & +33 & \\
\hline & $>102.9(>39.4)$ & +49 & $39.5^{\circ} \mathrm{C}$ \\
\hline \multirow[t]{3}{*}{ Organomegaly } & No & 0 & \\
\hline & Hepatomegaly or splenomegaly & +23 & Splenomegaly \\
\hline & Hepatomegaly and splenomegaly & +38 & \\
\hline \multirow{3}{*}{$\begin{array}{l}\text { Number of cytopenias } \\
\text { Defined as hemoglobin } \leq 9.2 \mathrm{~g} / \mathrm{dL}(\leq 5.71 \mathrm{mmol} / \mathrm{L}) \text { and } / \text { or } \\
\text { WBC } \leq 5000 / \mathrm{mm}^{3} \text { and } / \text { or platelets } \leq 110,000 / \mathrm{mm}^{3}\end{array}$} & 1 lineage & 0 & \\
\hline & 2 lineages & +24 & \\
\hline & 3 lineages & +34 & $\begin{array}{l}\mathrm{Hb} 7.7 \mathrm{~g} / \mathrm{dL}^{3} \text { WBC } \\
3700 / \mathrm{mm}^{3}, \text { plate- } \\
\text { lets } 27,000 / \mathrm{mm}^{3}\end{array}$ \\
\hline \multirow[t]{3}{*}{ Ferritin, ng/mL (or $\mu \mathrm{g} / \mathrm{L}$ ) } & $<2,000$ & 0 & \\
\hline & $2000-6000$ & +35 & \\
\hline & $>6000$ & +50 & $20,696 \mathrm{ng} / \mathrm{mL}$ \\
\hline \multirow[t]{3}{*}{ Triglyceride, mg/dL (mmol/L) } & $<132.7(<1.5)$ & 0 & \\
\hline & $132.7-354(1.5-4)$ & +44 & \\
\hline & $>354(>4)$ & +64 & $428 \mathrm{mg} / \mathrm{dL}$ \\
\hline \multirow[t]{2}{*}{ Fibrinogen, mg/dL (g/L) } & $>250(>2.5)$ & 0 & \\
\hline & $\leq 250(\leq 2.5)$ & +30 & $74 \mathrm{mg} / \mathrm{dL}$ \\
\hline \multirow[t]{2}{*}{ AST (aspartate aminotransferase), U/L } & $<30$ & 0 & \\
\hline & $\geq 30$ & +19 & $59 \mathrm{U} / \mathrm{L}$ \\
\hline \multirow[t]{2}{*}{ Hemophagocytosis features on bone marrow aspirate } & No & 0 & No \\
\hline & Yes & +35 & \\
\hline Total & & & $\begin{array}{l}269 \text { points (>99\% } \\
\text { probability of } \\
\text { hemophagocytic } \\
\text { syndrome) }\end{array}$ \\
\hline
\end{tabular}

treated successfully with JAK inhibitors and IL-1 or IL-6 blockers [11, 12].

Low dose ruxolitinib plus HLH-94 protocol has already been reported as a potential choice for sHLH [13]. Finally, in patients with severe active disease, a reduced dose of Etoposide (50-100 mg/mq once weekly) may be very effective [14].

\section{Case presentation \\ Patient information}

In May 2020 a 56-year-old Caucasian female without any relevant past medical history (no drugs taken or previous diseases referred), was hospitalized for fever up to $40{ }^{\circ} \mathrm{C}$, dry cough, ageusia and anosmia at Policlinic San Marco Hospital, Zingonia (Bergamo, Italy). No family history of diabetes, cardiovascular diseases, cancer, autoimmune disease (such as arthritis, vasculitis or lupus) or other relevant diseases were reported. She reached menopause at about 52 years old; her previous pregnancies proceeded without any complications. She has never smoked and she drinks alcoholic drinks occasionally (a glass of wine twice a week).

\section{Clinical findings}

The patient's clinical picture was characterized by fever up to $40{ }^{\circ} \mathrm{C}$, dry cough, ageusia and anosmia, which were significative of COVID-19.

\section{Diagnostic assessment}

During the hospitalization, total body CT-scan revealed polyserositis: pericardial effusion, pleuro-parenchymal fibrosis of the lung bases associated with bilateral pleural effusion and splenomegaly. Three SARS-Cov-2 nasopharyngeal swabs were performed and each of them resulted negative and multiple blood culture sets resulted negative. Viral infections (Epstein Barr virus EBV, Cytomegalovirus CMV, Human Immunodeficiency virus HIV, hepatotropic viruses and viruses transmitted by 
Table 2 HScore interpretation

\begin{tabular}{ll}
\hline Hscore & $\begin{array}{l}\text { Probability of } \\
\text { hemophagocytic } \\
\text { syndrome (\%) }\end{array}$ \\
\hline$\leq 90$ & $<1$ \\
$91-100$ & $\sim 1$ \\
$101-110$ & $1-3$ \\
$111-120$ & $3-5$ \\
$121-130$ & $5-9$ \\
$131-140$ & $9-16$ \\
$141-150$ & $16-25$ \\
$151-160$ & $25-40$ \\
$161-170$ & $40-54$ \\
$171-180$ & $54-70$ \\
$181-190$ & $70-80$ \\
$191-200$ & $80-88$ \\
$201-210$ & $88-93$ \\
$211-220$ & $93-96$ \\
$221-230$ & $96-98$ \\
$231-240$ & $98-99$ \\
$\geq 241$ & $>99$ \\
\hline
\end{tabular}

arthropods) were promptly ruled out, as well as atypical pneumonia by Mycoplasma or Chlamydia bacteria. Considering that Bergamo and nearby cities have been the most affected area in Italy by COVID-19, SARS-Cov-2 immunoglobulins G (IgG) were tested and found to be positive. In the meantime, we observed lowering fibrinogen values, occurrence of cytopenias (anaemia $<10 \mathrm{~g} / \mathrm{dL}$ and thrombocytopenia $<100.000 / \mathrm{mcl}$ ), increasing values of ferritin aspartate aminotransferase and triglycerides. Moreover, LDH and D-dimer were elevated, direct and indirect Coombs tests were negative, no schystocytes were observed at the morphological exam of the patient's blood smear, aptoglobin, bilirubin and reticulocytes were normal, activated partial thromboplastin time was slightly elevated (according to the inflammatory state) while prothrombin time was normal. Antinucleus antibodies, rheumatic factor, lupus anticoagulant and anti-cardiolipin antibodies were found negative. The individual risk of HLH the patient scored 269 points with $>99 \%$ probability of having the syndrome (HScore see Tables 1 and 2). HScore greater than 169 is 93\% sensitive and $86 \%$ specific for hemophagocytic syndrome. Therefore, a bone marrow biopsy was performed: the morphological and histological exams did not revealed aspects of hemophagocytosis. Functional (NK cell cytotoxicity and CD107a upregulation) and genetic testing were not performed, considering that abnormalities are rarely detected in adult patients and these tests are not generally recommended in adult HLH [14]. Moreover, in this particular historical period of global health crisis the execution of more advanced tests such as next generation sequencing was not promptly available. A diagnosis of HLH was made according to HLH-2004 criteria (presence of fever, splenomegaly, cytopenias, hypofibrinogenemia, hypertriglyceridemia, ferritin $>500 \mathrm{mcg} / \mathrm{L}$ ) and HScore.

\section{Therapeutic interventions}

At the beginning the patient was treated with empiric antibiotic therapy (ceftriaxone), without any improvement of her clinical conditions and further empiric antibiotic regimens (piperacillin-tazobactam, teicoplanin, meropenem, linezolid, levofloxacin) were unsuccessful. The patient was diagnosed with hemophagocytic syndrome likely related to SARS-Cov-2 infection as a

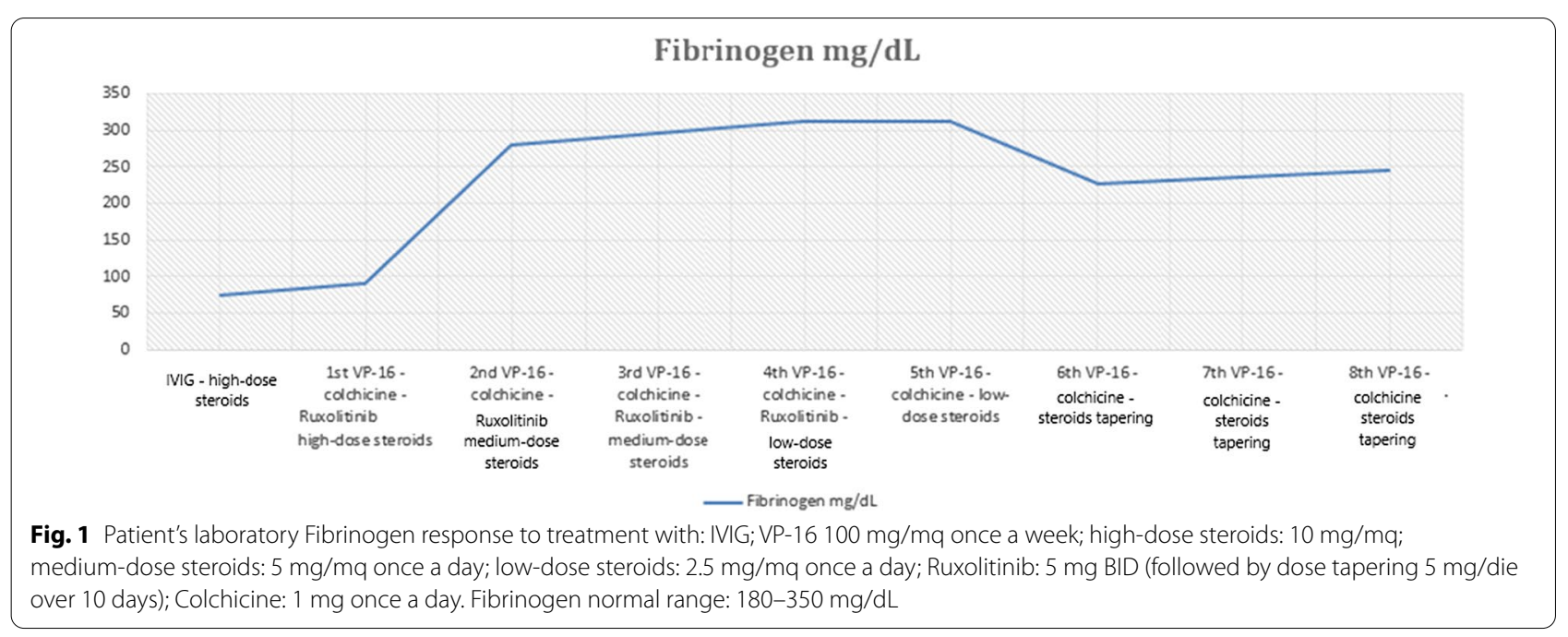




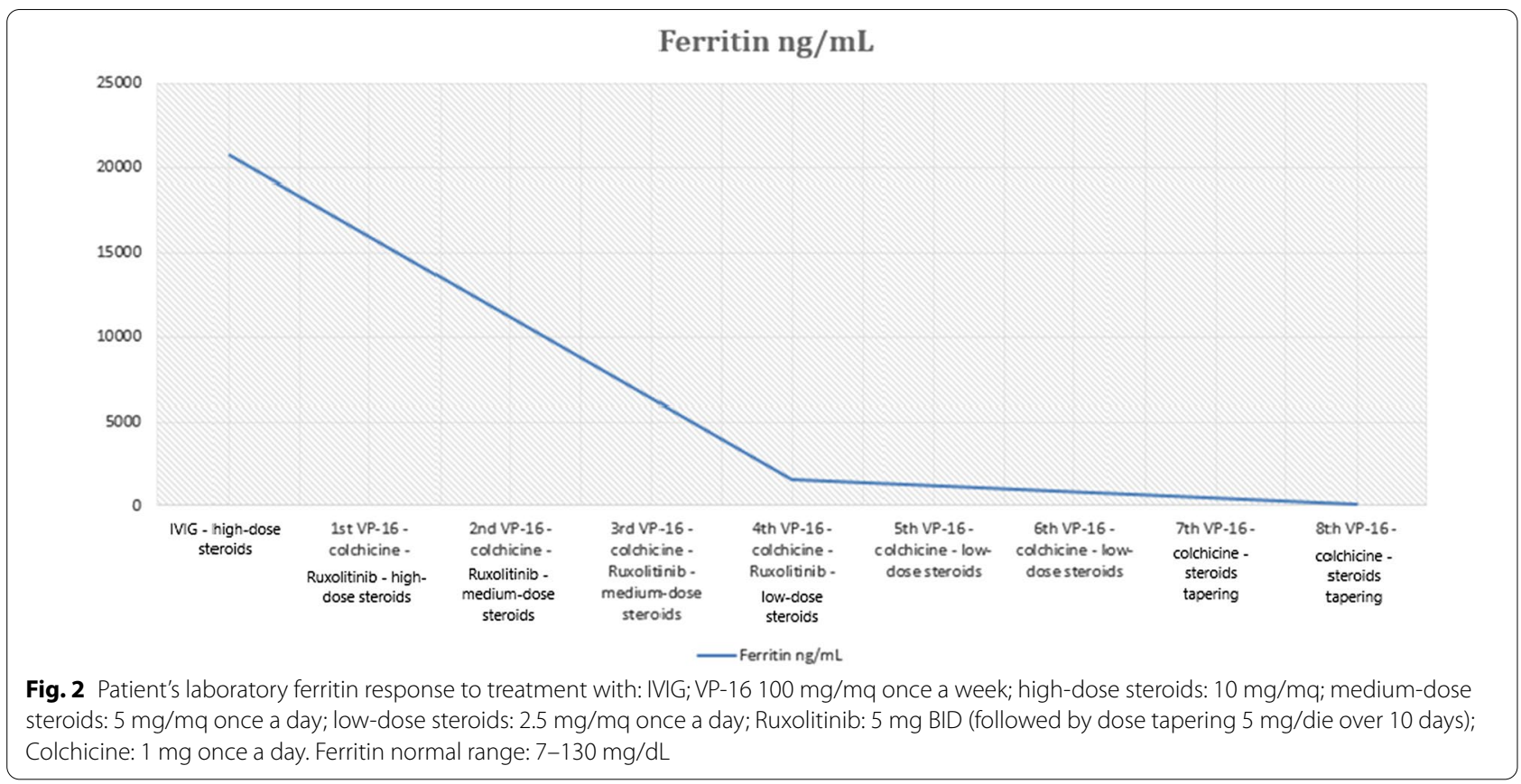

trigger factor and was treated with high-dose steroids (dexamethasone $10 \mathrm{mg} / \mathrm{mq}$ once a day D1-14, $5 \mathrm{mg} / \mathrm{mq}$ D15-28, $2.5 \mathrm{mg} / \mathrm{mq}$ after 1 month for maintenance treatment followed by slow reduction) and high dose intravenous immunoglobulins (IVIG) $1 \mathrm{~g} / \mathrm{kg}$ for 2 consecutive days. Due to the persistence of fever and a further drop in platelets haemoglobin and fibrinogen after a week from the beginning of the immunosuppressive therapy, lowdose Ruxolitinib (5 mg bid) for a month, which was discontinued after a tapering over 10 days $(5 \mathrm{mg} / \mathrm{die})$, and Etoposide (VP-16) $100 \mathrm{mg} / \mathrm{mq}$ once weekly for 8 weeks were added to the treatment, while colchicine $(1 \mathrm{mg}$ once a day) therapy was administered for 3 months, considering the reported efficacy in the treatment of acute pericarditis [15]. In addition, antiviral (acyclovir $400 \mathrm{mg}$ PO BID), antibiotic (sulfamethoxazole/trimethoprim three times weekly) and heparin (enoxaparin $4000 \mathrm{UI} \mathrm{sc/die)}$ prophylaxes were prescribed. During the treatment a remarkable improvement in the patient's symptoms as well as the normalization of blood count and of fibrinogen and ferritin values (see Figs. 1 and 2), the disappearance of fever and the remission of polyserositis.

\section{Follow-up and outcomes}

After the end of the treatment, the patient has been followed on a regular basis and the disease is still in remission. Serial blood tests revealed normal whole blood count (WBC) and normal values of fibrinogen and ferritin (see Figs. 1 and 2). In addition, CT scans at 3 and 6 months after the end of treatment as well as the echocardiography documented the remission of the patient's polyserositis and of splenomegaly.

\section{Discussion and conclusions}

The diagnosis of HLH can be very challenging. An increased awareness of this disease together with a rapid therapeutic approach can improve the prognosis [9]. Nevertheless, HLH is still a severe and potentially fatal disease. A diagnosis of HLH was made according to HLH-2004 criteria (presence of fever, splenomegaly, cytopenias, hypofibrinogenemia, hypertriglyceridemia, ferritin $>500 \mathrm{mcg} / \mathrm{L}$ ) and HScore. Thrombotic thrombocytopenic purpura, disseminated intravascular coagulation, autoimmune haemolytic anemia and thrombocytopenia (Evans' syndrome) as well as catastrophic antiphospholipid syndrome were considered as part of differential diagnosis. Even linezolid myelosuppressive side effects were valuated as a cause of cytopenia and therefore the drug was promptly suspended when it was shown inefficacious for the treatment of the patient's fever. Since other common causes of sHLH (malignancies, viral infections or autoimmune-rheumatologic diseases) were excluded, we suggest that HLH-like syndrome could develop at a distance from the Sars-Cov-2 infection, as a result of persistent inflammatory state. In addition, we underline the treatment with low dose ruxolitinib plus etoposide as a potential choice for COVID19 related HLH [13, 14]. Noteworthy, it is important to collect more information about potential persistent inflammatory state related to previous COVID-19 and 
therefore develop and improve therapy of HLH secondary to Sars-Cov-2 infection.

\begin{abstract}
Abbreviations
HPS: Hemophagocytic syndrome; SHLH: Secondary forms of HLH; COVID-19: Coronavirus disease 19; MAS: Macrophage-activation syndrome; CT: Computed tomography; SARS: Severe acute respiratory syndrome; EBV: Epstein Barr virus; CMV: Cytomegalovirus; HIV: Human immunodeficiency virus; IVIG: Intravenous immunoglobulins.
\end{abstract}

\section{Acknowledgements}

Not applicable.

\section{Authors' contributions}

FM, AD and MMP have made substantial contributions to the conception and design of the work, to the acquisition, analysis and interpretation of data; FM drafted the manuscript; BF, DDM, AF, MM, CG, GG and MT have drafted the work or substantively revised it. All authors have approved the submitted version (and any substantially modified version that involves the author's contribution to the study) and have agreed both to be personally accountable for the author's own contributions and to ensure that questions related to the accuracy or integrity of any part of the work, even ones in which the author was not personally involved, are appropriately investigated, resolved, and the resolution documented in the literature. All authors read and approved the final manuscript.

\section{Funding}

Not applicable.

\section{Availability of data and materials}

The datasets used and/or analysed during the current study are available from the corresponding author on reasonable request.

\section{Declarations}

\section{Ethics approval and consent to participate}

Written informed consent was obtained from the patient for publication of this case report and any accompanying images.

\section{Consent for publication}

Informed written consent was obtained from individual participant included in the study.

\section{Competing interests}

The authors have no competing interest to declare.

Received: 7 November 2020 Accepted: 21 June 2021

Published online: 13 August 2021
References

1. Ramos-Casals M, et al. Adult haemophagocytic syndrome. The Lancet. 2014;383(9927):1503-16.

2. Emile JF, Abla O, Fraitag S, et al. Revised classification of histiocytoses and neoplasms of the macrophage-dendritic cell lineages. Blood. 2016;127(22):2672-81.

3. Sepulveda FE, de Saint BG. Hemophagocytic syndrome: primary forms and predisposing conditions. Curr Opin Immunol. 2017:49:20-6.

4. Rouphael NG, Talati NJ, Vaughan C, et al. Infections associated with haemophagocytic syndrome. Lancet Infect Dis. 2007;7(12):814-22.

5. Daver N, McClain K, Allen CE, et al. A consensus review on malignancyassociated hemophagocytic lymphohistiocytosis in adults. Cancer. 2017;123(17):3229-40.

6. Sadaat M, Jang S. Hemophagocytic lymphohistiocytosis with immunotherapy: brief review and case report. J Immunother Cancer. 2018;6(1):49.

7. Henet Jl, Home A, Aricò M, et al. HLH-2004: diagnostic and therapeutic guidelines for hemophagocytic lymphohistiocytosis. Pediatr Blood Cancer. 2007:48(2):124-31.

8. Fardet L, Galicier L, Lambotte $\mathrm{O}$, et al. Development and validation of the HScore, a score for the diagnosis of reactive hemophagocytic syndrome. Arthritis Rheumatol. 2014;66(9):2613-20.

9. England JT, Abdulla A, Biggs CM, et al. Weathering the COVID-19 storm: lessons from hematologic cytokine syndromes. Blood Rev. 2020. https:// doi.org/10.1016/j.blre.2020.100707.

10. Iba T, Levy JH, Connors JM, et al. The unique characteristics of COVID-19 coagulopathy. Crit Care. 2020;24:360.

11. Soy M, Atagunduz P, Atagunduz I, Sucak GT, et al. Hemophagocytic lymphohistiocytosis: a review inspired by the COVID-19 pandemic. Rheumatol Int. 2020. https://doi.org/10.1007/s00296-020-04636-y.

12. Ruscitti P, Beradicurti O, et al. Severe COVID-19, another piece in the puzzle of the hyperferritinemic syndrome. An immunomodulatory perspectve to alleviate the storm. Front Immunol. 2020;11:1130.

13. Wang $H$, Gu J, Liang $X$, Mao X, Wang Z, et al. Low dose ruxolitinib plus HLH-94 protocol: a potential choice for secondary HLH. Semin Hematol. 2019;9:28.

14. La Rosee P, et al. Recommendations for the management of hemophagocytic lymphohistiocytosis in adults. Blood. 2019;133(23):2465-77.

15. Imazio M. Colchicine for pericarditis. Trends Cardiovasc Med. 2015;25(2):129-36. https://doi.org/10.1016/j.tcm.2014.09.011.

\section{Publisher's Note}

Springer Nature remains neutral with regard to jurisdictional claims in published maps and institutional affiliations.
Ready to submit your research? Choose BMC and benefit from:

- fast, convenient online submission

- thorough peer review by experienced researchers in your field

- rapid publication on acceptance

- support for research data, including large and complex data types

- gold Open Access which fosters wider collaboration and increased citations

- maximum visibility for your research: over 100M website views per year

At BMC, research is always in progress.

Learn more biomedcentral.com/submissions 